\title{
Baseline Study of Sputum Microscopy for Diagnosis of Tuberculosis in Western Region of Nepal
}

\author{
Amrita Dhakal', Samata Nepal'2, Alok Atreya ${ }^{3}$ and Basista Rijal ${ }^{1}$ \\ 1Department of Microbiology, Devdaha Medical College and Research Institute, Rupandehi, Nepal \\ ${ }^{2}$ Department of Community Medicine, Devdaha Medical College and Research Institute, Rupandehi, Nepal \\ ${ }^{3}$ Department of Forensic Medicine, Devdaha Medical College and Research Institute, Rupandehi, Nepal
}

\begin{abstract}
Introduction: Tuberculosis is a major health issue in Nepal. Early detection of tuberculosis is essential to identify the case which limits the transmission of tuberculosis and builds an effective approach of tuberculosis control policy. Therefore, the present study is aimed to assess the case of tuberculosis by sputum smear examination.

Methods: A prospective study was conducted in a tertiary care hospital of Western Nepal. Two sputum samples were collected from each suspect - spot specimen on the first day and one early morning specimen on the second day. The standard protocol of Ziehl Neelsen stain was applied to detect the acid fast bacilli.

Results: Out of 280 smears from suspected patients, only 30 showed smear positivity (10.7\%). Among the total identified positive case of tuberculosis (30/280), the highest rate was observed in the age group of 56-65 years. Males (56.7\%) were highly affected by tuberculosis than females (43.3\%). The minimum age of the suspects was two years and maximum age was of 105 years with mean age of 53.6 years.

Conclusions: It is concluded that prevalence of tuberculosis is high in patients attending tertiary care hospital in Western region of Nepal, which is slightly higher than the annual report of National Tuberculosis Program 2017. Incidence of pulmonary tuberculosis is higher in males as compared to females.
\end{abstract}

Key Words: DOTS; prevalence, pulmonary tuberculosis; Ziehl Neelsen stain

Correspondence: Amrita Dhakal, Department of Microbiology, Devdaha Medical College and Research Institute, Rupandehi, Nepal. Email: amudhakal3@gmail.com

DOI: http://dx.doi.org/10.3126/mjsbh.v17i2.20343

Submitted on: 2018-06-19

Accepted on: 2018-06-28

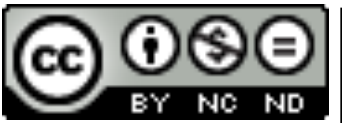

This work is licensed under creative common license:

http://creativecommons.org/licenses/by-nc-nd/4.0/ C MJSBH 2018 


\section{INTRODUCTION}

World Health Organisation (WHO) global tuberculosis report estimated 10.4 million people fell ill with tuberculosis and 1.3 million people were killed by tuberculosis among HIV negative people and 37,4000 people among HIV positive people. ${ }^{1}$ Tuberculosis is a major health issue in Nepal and it is one of the leading causes of death throughout the country. ${ }^{2}$

National Tuberculosis Program (NTP) launched Direct Observed Treatment short course (DOTS) policy in 1996. Since then the prevalence of tuberculosis cases has declined but still 6,000 to 7,000 people expire each year because of tuberculosis. ${ }^{2}$ Timely detection of tuberculosis is essential to identify the cases which limits the transmission of tuberculosis and builds an effective approach of tuberculosis control policy. ${ }^{3}$ Sputum smear microscopy has been considered as a key procedure for the detection of pulmonary tuberculosis in developing countries. ${ }^{4}$ Smear examinations by Ziehl Neelsen stain is a conventional technique for the diagnosis and treatment of tuberculosis. ${ }^{5}$

In Nepalese context, more than half of the tuberculosis (57\%) cases were detected in Terai belt in $2017 .{ }^{2}$ Relatively there are fewer number of studies conducted in various region but still study of tuberculosis based on sputum microscopy has not yet been implemented in Western region of Nepal. Therefore, the present study is aimed to assess the case of tuberculosis by sputum smear examination.

\section{METHODS}

A prospective study was conducted in tertiary care hospital of Western region of Nepal from April 2015 to April 2017. This hospital is conducting Direct Observed Treatment Short Course (DOTS) clinic where the patients of pulmonary tuberculosis get their treatment and further assessment during follow-up period. A total of 280 suspected patients of pulmonary tuberculosis were included in the study.

Each suspected patient was instructed to take a deep breath and expectorate mucopurulent sputum according to the guidelines of WHO and National Tuberculosis Control Program.1,2 Two sputum samples were collected from each suspects - spot specimen on the first day and one early morning specimen on the second day. Suspected patients unable to provide two sputum (spot-morning) specimens and salivary specimens were excluded in the study. All specimens were collected in clean, sterile, leak-proof, wide mouth container. Uniform and consistent smear were aseptically prepared with loop holding purulent portion of sputum sample, air dried and then heat fixed. Staining was done as per the standard protocol of Ziehl Neelsen staining technique. Acid fast bacilli were detected under microscope and reports were prepared as per the grading system of World Health Organisation. ${ }^{1}$

Data thus collected was entered and analysed using SPSS software (Version 21). This study was approved by institutional ethics and review committee.

\section{RESULTS}

A total of 280 suspected patients included in the present study where the highest number of suspects was above 65 years $(33.6 \%)$ and least number of suspects was in the age below 15 years $(2.1 \%)$. The youngest suspect was two years of age and the highest age was 105 years with mean age of 53.6 years. Out of 280 suspects, 30 smears showed smear positivity $(10.7 \%)$. Among the total identified positive case of tuberculosis (30/280), the highest rate was observed in the age group of 56 to 65 years (30\%) and the lowest rate of positive cases 
Table 1. Demographic and year wise distribution of respondents

\begin{tabular}{|l|r|r|r|}
\hline Variables & Categories & \multicolumn{1}{c|}{$\begin{array}{c}\text { Number } \\
(\%)\end{array}$} & $\begin{array}{c}\text { Smear } \\
\text { positivity } \\
(\%)\end{array}$ \\
\hline $\begin{array}{l}\text { Age } \\
\text { groups }\end{array}$ & $0-15$ & $6(2.1)$ & $0(0)$ \\
\cline { 2 - 4 } & $16-25$ & $33(11.8)$ & $8(26.6)$ \\
\cline { 2 - 4 } & $26-35$ & $32(11.4)$ & $5(16.7)$ \\
\hline \multirow{2}{*}{ Year } & $36-45$ & $24(8.6)$ & $2(6.7)$ \\
\hline & $46-55$ & $33(11.8)$ & $2(6.7)$ \\
\hline & $56-65$ & $58(20.7)$ & $9(30.0)$ \\
\hline Total & 2015 & $44(15)$ & $5(11.9)$ \\
\hline & 2016 & $77(27.5)$ & $13(16.9)$ \\
\hline & & $161(57.5)$ & $12(7.5)$ \\
\hline & & 280 & $30(10.7)$ \\
\hline
\end{tabular}

was seen in the age group of 36 to 45 years $(6.7 \%)$ and 46 to 55 years $(6.7 \%)$ (Table 1$)$.

The hospital setting had increased number of yearly sample collection from 42 (2015) to 161 (2017). The highest smear positivity was detected in 2016 (16.9\%) and the lowest was in 2017 (7.5\%). In 2015 , smear positivity was on an average $(11.9 \%)$ (Table 1).

Table 3. Grade of smear according to the guidelines of World health Organisation

\begin{tabular}{|l|r|r|}
\hline $\begin{array}{l}\text { Number of } \\
\text { AFB seen }\end{array}$ & \multicolumn{1}{c|}{ Grading } & \multicolumn{1}{|c|}{ Result (\%) } \\
\hline $\mathbf{0}$ in $\mathbf{1 0 0}$ field & No AFB seen & $250(89.3)$ \\
\hline Total positive & & $30(10.7)$ \\
\hline $\mathbf{1 - 9 / 1 0 0 ~ f i e l d ~}$ & Scanty & $0(0)$ \\
\hline $\begin{array}{l}\text { 10-99/100 } \\
\text { field }\end{array}$ & $1+$ & $13(43.3)$ \\
\hline $\mathbf{1 - 1 0 / f i e l d ~}$ & $2+$ & $7(23.3)$ \\
\hline$>$ 10/field & $3+$ & $5(16.7)$ \\
\hline $\begin{array}{l}\text { Grade not } \\
\text { recorded }\end{array}$ & & $5(16.7)$ \\
\hline
\end{tabular}

Table 2. Gender distribution of respondents

\begin{tabular}{|l|r|r|}
\hline \multicolumn{2}{|c|}{ Gender } & \multicolumn{1}{l|}{$\begin{array}{l}\text { Smear } \\
\text { positivity (\%) }\end{array}$} \\
\hline Female & $117(41.8)$ & $13(43.3)$ \\
\hline Male & $163(58.2)$ & $17(56.7)$ \\
\hline Total & $280(100.0)$ & $30(100.0)$ \\
\hline
\end{tabular}

Out of total suspected patients, the participation of male was higher $163(58.2 \%)$ than female 117 (41.8\%). Males (56.7\%) were highly affected by tuberculosis than females (43.3\%) (Table 2). From a total of 30 positive samples, $13(43.3 \%)$ smears were in a proportion of $1+$ smear grade, $7(23.3 \%)$ were in a proportion of $2+$ grade and least number of smears $(5,16.7 \%)$ were in a proportion of $3+$ grade. There were five samples whose grade was unknown (Table 3).

\section{DISCUSSION}

Sputum microscopy is gateway to diagnose the case of tuberculosis and it is very simple, convenient requiring less effort and can be performed on any hospital setting where only fundamental resources are available.

In our study, overall smear positivity was found to be $10.7 \%$ on average which is in accordance with the annual report of National Tuberculosis Program of Nepal, 2017. ${ }^{2}$ The study done in Southern region of Nepal by Shrestha et al. ${ }^{6}$ also found similar result (13.6\%). Similarly, the various studies done in different countries are in favour with our results [Uddin et al. ${ }^{7}$ (8\%), Ndubuisi et al. ${ }^{8}(12.3 \%)$ and Dinna et al. $\left.{ }^{9}(10 \%)\right]$. But the study done in Central region of Nepal by Tiwari et al. ${ }^{10}$ had found very high rate of smear positivity (32.4\%) as compared to our results. Variations in the percentage of smear positivity may occur due to the size of the sample collected and it also depends on the prevalence of tuberculosis in particular area. 
Our study revealed that majority of the participants were males $(58.2 \%)$ than females $(41.8 \%)$ which is in line with the observation of Mahato et al. ${ }^{11}$ where the percentage of male respondents was $(62.57 \%)$ and female was $(37.43 \%)$.

In the present study, incidence of tuberculosis was relatively higher in male participants $(56.7 \%)$ as compared to females (43.3\%) which is in concordance with the annual report of National Tuberculosis Program of Nepal, 2017.2 Similar result was obtained by Amgain et al. ${ }^{12}$ where prevalence of tuberculosis was higher in males $(55.56 \%)$ than females (44.44\%). A study done by Dinna et al. ${ }^{9}$ had also observed the similar finding where the higher proportion of smear positivity was reported in male respondents $(60 \%)$ than females (40\%). Males are occupationally active in the developing countries like Nepal. Therefore, there is higher chance of aerosol exposure of tuberculosis in areas such as manufacturing complex and dairy industry where multiple numbers of people work together.

This study demonstrated that the majority of the tuberculosis patients were in the age group of 56 to 65 years $(30 \%)$ which is in line with the study of Shrestha et al. ${ }^{6}$ where the highest prevalence rate was among the age group of 41 to 60 years $(17.2 \%)$. The result found in the present study is totally in contrast with the study of Dinna et al. ${ }^{9}$ where there was no smear positive case in the age group 45 to 64 years. In our study, there was higher rate of positivity in the age range of 16 to 25 years (26.6\%) and 26 to 35 years (16.7\%). Generally tuberculosis is prevalent in the productive age group and mobilisation of employee at this age group can be infective to debilitating persons.

In the present study, there was no case of tuberculosis among the age group below 15 years. This is in contrast with the result of Sreerama Reddy et al. ${ }^{13}$ where $17.2 \%$ of tuberculosis infected were children. Similarly, annual report of National Tuberculosis Programme 2017 stated that the rate of tuberculosis among children is around 5.6\%. Another study done in Eastern Nepal by Yadav et al. ${ }^{14}$ found that $20 \%$ of patients infected with tuberculosis were at the age group of 0 to 19 years. In our study, sample collection among paediatric population was very low (2.6\%). Therefore, accurate results could not be ruled out properly. Normally children are unable to expectorate the sputum hence the preferable specimen is bronchoalveolar lavage and there is possibility to detect tubercle bacilli.

\section{CONCLUSIONS}

The prevalence of tuberculosis is high in patients attending tertiary care hospital, which is slightly higher than the annual report of National Tuberculosis program 2017. Incidence of pulmonary tuberculosis is higher in males as compared to females. There was increase in number of yearly sample collection in past three years. This implies that people in this area are more concerned about the tuberculosis despite the low literacy rate. Awareness programs on television, radio, newspapers and internet might had made a positive influence. However, as the prevalence rate is high than the annual national report, awareness campaigns should be more effective and should reach every nook and corner of the rural community. People should be made aware and realise that $\mathrm{TB}$ is not a stigma, rather a curable bacterial infection, and the treatment is free of cost once a confirmatory diagnosis is made. The present study highlights the low number of childhood TB. Sputum microscopy alone is unable to detect TB in paediatric population. Awareness programs in school in the form of debates, quiz, talk shows and poster completion which involves the students might play a positive role. 
To cite this article: Dhakal A, Nepal S, Atreya A, Rijal B. Baseline study of sputum microscopy for diagnosis of tuberculosis in Western region of Nepal. MJSBH. 2018;17(2):19-24.

Conflict of Interest: None declared

\section{REFERENCES}

1. World Health Organisation. Global Tuberculosis Report. WHO: 2017.

2. National Tuberculosis Programme Nepal NTPN Annual Report 2017. Ministry of Health and Population. Government of Nepal. Kathmandu: 2017.

3. Meseret W, Mandie M, Ibrahim S, Ziyadu B, Markos N, Mulugeta M, et al. Agreement between Direct Fluorescent Microscopy and Ziehl-Neelsen Concentration Techniques in Detection of Pulmonary Tuberculosis in Northwest Ethiopia. J Health Sci. 2017;27(5):459.

DOI: $10.4314 /$ ejhs.v27i5.3

4. Desikan P. Sputum smear microscopy in tuberculosis: Is it still relevant. Indian J Med Res. 2013;137:442-4.

5. Myneedu VP, Verma AK, Sharma PP, Behera D. A pilot study of same day sputum smear examination, its feasibility and usefulness in diagnosis of pulmonary Tb. Indian J Tuberc. 2011;58:160-7.

PMID: 22533165

6. Shrestha S, Shakya B, Shrestha P. Prevalence of Pulmonary Tuberculosis among the suspected patients visiting tertiary care hospital in Birgunj, Nepal. Janaki Med College J Med Sci. 2013;1(1):48-52.

DOI: $10.3126 /$ jmcjms.v1i1.7886

7. Uddin MK, Chowdhury MR, Ahmed S, Rahman MT, Khatun R, van Leth F, et al. Comparison of direct versus concentrated smear microscopy in detection of pulmonary tuberculosis. BMC research notes. 2013 Dec;6(1):291.

DOI: https://doi.org/10.1186/1756-0500-6-291

8. Ndubuisi NO, Azuonye OR, Victor NO, Robert OC, Vivian O. Front-loaded sputum microscopy in the diagnosis of pulmonary tuberculosis. Int J Mycobacteriology. 2016;5:489-92.

DOI: 10.1016/j.ijmyco.2016.04.005

9. Dinna AN, Getachew AM, Anteneh TT. Prevalence of Smear-Positive Tuberculosis among Patients Who Visited Saint Paul's Specialized Hospital in Addis Ababa, Ethiopia. BioMed Res Int. 2017.

DOI: $10.1155 / 2017 / 6325484$

10. Tiwari BR, Karki S, Ghimire P, Sharma B, Malla S. Factors associated with high prevalence of pulmonary tuberculosis in HIV-infected people visiting for assessment of eligibility for highly active antiretroviral therapy in Kathmandu, Nepal. WHO South-East Asia J Public Health. 2012;1(4):404-11.

DOI: $10.4103 / 2224-3151.207042$

11. Mahato RK, Laohasiriwong W, Vaeteewootacharn K, Koju R, Bhattarai R. Major Delays in the diagnosis and management of Tuberculosis Patients in Nepal. J Clinical Diagnostic Res. 2015;9(10):5-9. 
DOI: $10.7860 / J C D R / 2015 / 16307.6633$

12. Amgain K, Maharjan M. Prevalence of Pulmonary Tuberculosis in Jutpani VDC, Chitwan, Nepal. Nepalese J Zoology. 2015;3(1):5.

13. Sreeramreddy CT, Ramkrishnareddy N, Shah RK, Baniya R, Swain PK. Clinico-epidemiological profile and diagnostic procedures of pediatric tuberculosis in a tertiary care hospital of western Nepal-a case series analysis. BMC Pediatr. 2010;10:57.

DOI: $10.1186 / 1471-2431-10-57$

14. Yadav DK, Jha N, Pokharel PK, Niraula SR, Bhattacharya SK, Nagesh S. Study on the prevalence of pulmonary tuberculosis among HIV positive attending HIV clinics in Eastern Nepal. SAARC J Tuber Lung Dis HIV/AIDS. 2011;8(1):1-8.

DOI: $10.3126 /$ saarctb.v8i1.5885 